\title{
The Investigation of Competence of Teachers and Kindergartens in Terms of Movement Education Achievements in Pre-School Education Program
}

\author{
Fehmi ÇALIK ${ }^{1}$ \\ İsmail ÇELİK ${ }^{2}$ \\ Selami SÖNMEZ ${ }^{3}$
}

'Sakarya University, Sakarya, Turkey

'A rr İbrahim Çeçen University, A $\breve{g} r$, Turkey

'Atatürk University, Erzurum, Turkey

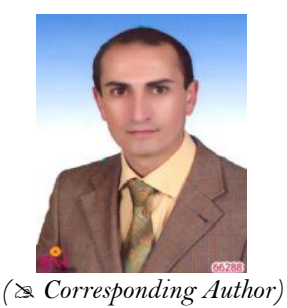

\begin{abstract}
Movement education is an education that has an important place in pre-school education and supports all development areas. However, although it is so important, condition in which movement education is included in the pre-school education program and the adequacy of teachers and schools to be able to provide such education is the purpose of our research. The research was a qualitative research and was applied 38 teachers working in 10 kindergartens in the central province of Ağrı. The data were analyzed by content analysis technique. According to research findings, $79 \%$ of the teachers stated that they found themselves inadequate at the point of giving motion training. In addition, $90 \%$ of participants stated that schools are also inadequate in terms of materials and facilities. According to the results of the research, teachers stated that they did not take enough courses to give this education during undergraduate education as the reason for insufficient points of motion training. The results of the research show that, at the point of the movement training, the teachers who are graduated from physical education and sport teachers can be employed in the preschool education institutions which are a possible measure to solve this problem.
\end{abstract}

Keywords: Movement education, Preschool, Physical education and sports

Citation | Fehmi CALIK; İsmail CELİK; Selami SÖNMEZ (2018). The Investigation of Competence of Teachers and Kindergartens in Terms of Movement Education Achievements in Pre-School Education Program. Journal of Education and e-Learning Research, $5(3): 179-184$.

History:

Received: 5 March 2018

Revised: 18 June 2018

Accepted: 13 August 2018

Published: 10 October 2018

Licensed: This work is licensed under a Creative Commons

Attribution 3.0 License (cc)

Publisher:Asian Online Journal Publishing Group

\section{Contents}

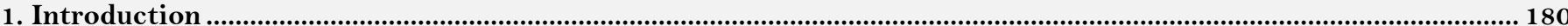

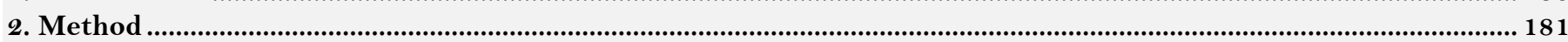

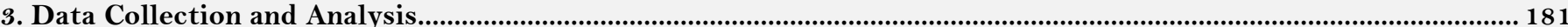

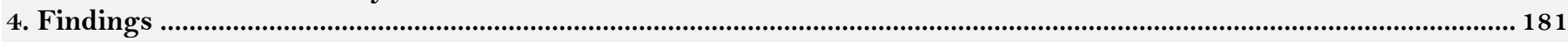

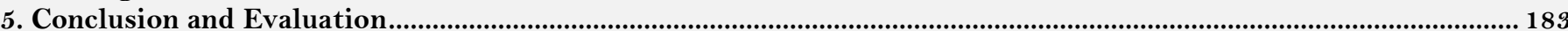

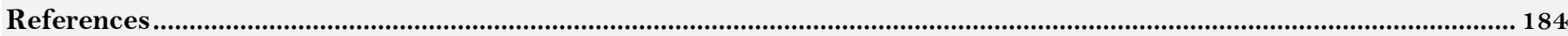




\section{Introduction}

Mankind must act in order to be able to perform their vital activities from birth to death. A number of physical exercises are required, which are inherited with genetic characteristics and which are to be acquired later and closely related to all the developmental areas of children. These requirements are considered to be given within 072 months, a developmentally important period prior to the elementary school period, which is regarded as the beginning of literacy education. This period is defined as the period of pre-school education and it is now more important in our country as it is in the developed countries, because this period is the period when children are the most active (Ozer and Ozer, 2004). Pre-school education is a period in which the basic skills required by the child are acquired and the child is prepared for primary school. It is a period in which the psychomotor it is accepted as a period in which the area should be considered the most. The psychomotor area is developed with sports, which is the primitive form, in children. In this respect, it is vital to make children like the sport that contributes to the education of the soul (Gillet, 1975).

Although the movement is a natural part of human life, it has always been neglected as much as daily. In the learning of basic mobility skills, experience has an important place and it affects mental and social development along with physical development. These skills, which are based on preschool education, need to be encouraged throughout the whole education life. For this reason, it is important for the quality of life for the next period to organize library by collecting data for these movements on a regular basis in order to develop basic movement skills of pre-school children (Cools et al., 2009). Considering the studies made at the point where children's psychomotor developments are taken in the forefront, the importance of children's physical, cognitive and social education as a whole is emphasized in the book of children and animation prepared by Calık (2006) and it is stated that the teaching of movements is vital.

In our educational institutions, training programs that support mental development are being implemented extensively. However, at the point of personality development, the way to use the body correctly is through movement training. The child underpins the next sports life through pre-school activities and exercises. For the movement trainings to be made in the preschool period, a movement training program should be established together with the related departments of the university, and the pre-school teachers should be guided by the educational tools equipped with concrete examples. In the book titled "Designing Pre-School Movement Programs" published by Sanders (1992) preliminary information on the selection, planning and implementation of movement training to be applied to 3-5 year-old children was given, and around 100 activities are showed with jumping, jumping, running, rounding and balancing skills, and these activities have been reinforced with sample lessons so as to help the teachers to get closer to the sport and develop themselves. Within the framework of a project titled "Investigation of the Effects of Physical Education and Sports Activities on the Development of Basic Motor and Social Skills of Preschool Children" by Özyürek and his colleagues in order to meet the need of movement of the children in preschool period and to support social skills, a program was developed to support the movement and social skills of the age group children. In fact, the program is considered to be a worthwhile work in terms of its importance, even though it contains simple activities for the basic movements that preschool teacher candidates can already apply (Ozyürek et al., 2015a).

It is aimed to gain recognition of the bodies of children by sports and to gain sports habits (Ozyürek et al., 2015b). It is also an undeniable fact that the sportive activities and movement education in early childhood contributed to the healthy growth of the child and it is an important contribution to the fight against obesity that the whole world is struggling with today (Kerkez, 2012; Celik and Sahin, 2013). When we look at the pre-school education program that is applied in our country, we can see that it is composed of the achievements and indicators created for each development area, separated by the following development areas:

Table-1. Achievements in terms of Development areas in Pre-school Education Program

\begin{tabular}{l|c|c}
\hline Development Area & Number of Achievements & Percentage \\
\hline Language Development: & 12 & 19 \\
\hline Social Emotional Development: & 17 & 27 \\
\hline Cognitive Development: & 21 & 33 \\
\hline Psychomotor Development: & $\mathbf{5}$ & $\mathbf{8}$ \\
\hline Self-care Ability: & $\mathbf{6 3}$ & 13 \\
\hline \multicolumn{2}{l}{ Total } & $\mathbf{1 0 0}$ \\
\hline
\end{tabular}

It is found that when the achievements related to motor development in the pre-school education program are compared with other achievements, it has the lowest numerical rate. We believe that a small number of psychomotor development achievements in the pre-school period, where physical development is so important, are due to the fact that the creation of the program is only considered in the narrow frame and that the committee includes only members and teachers of pre-school education and child development. This area should be put forward as a study which is expected to be carried out with participation of the commission from all disciplines, because it is a field that deals with all disciplines. The psychomotor skills in the 2013 Pre-School Education Program have been expressed as follows ${ }^{1}$.

Achievement 1. Makes displacement movements. (Indicators: Warm up and cool down with a guide, walk in direction, run in direction, jump from a certain height, jump to a certain height, climb to a certain height, descend from a climbing height, jump over an obstacle and jump over an obstacle. Jump on two foot a certain distance. Jumps a certain distance on one foot. Rounds in the specified distance. Goes by crawling a certain distance. Jumps forward on two foot from the specified point. Makes a step of slipping and travels at a certain distance. Makes a gallop and goes at a certain distance. Travels at specific distance.

1 (http://tegm.meb.gov.tr/meb_iys_dosyalar/2013_04/04124340_programkitabi.pdf) 
Achievement 2. Balance moves. (Indicators: transfers weight from one point to another, makes equilibrium movements related to jumping, putting, starting, stopping, standing on one foot, jumping on one foot, making balance movements individually and associatively, walking on the line in the direction, walking on balance board in the direction.)

Achievement 3. makes movements that require object control. (Indicators: Controls objects individually and in association with each other. Shoots over the shoulder with a small ball. Holds the throwing ball with hands. Runs to the standing ball and strikes with the foot. Strikes the small ball with one hand with the ground Strike the fixed ball with the paddle/bat. Puts objects of different size and weight into the target, removes objects, moves, pushes, pulls, skips.)

Achievement 4. Makes movements that require the use of small muscles. (Indicators: Collect objects, Collect objects from the cap, Collect objects vertically / Side by side / Interiors, Arrange objects, Sequence objects with different materials Combine objects in a way that will create new shapes, folds in different shapes, uses various materials to make drawings, objects tear, squeeze, pulls / stretches, opens / closes, turns, shapes material with its handles, shapes the material using tools, keeps the pencil correctly, provides pencil control, draws lines)

Achievement 5. Music and rhythm accompanied by movement. (Indicators: performs rhythm work using body, objects and percussion instruments, makes simple dance steps, dances with music and rhythm, makes various movements one after the other with music and rhythm)

The purpose of this research is to examine the adequacy of the achievements of the movement education in the Pre-School Education Program in terms of teachers and kindergartens.

\section{Method}

Content analysis method was used in the study. Content analysis is a method that is generally used in the field of sports and social sciences (Yıldırım and Simşek, 2011) based on the transformation of the information received from the participants participating in the research into numerical expressions (Ylldırım and Simşek, 2011). The study group consists of 10 kindergartens, located in the central province of Ağrı, and 38 teachers working in these kindergartens. The participation is done on the basis of volunteerism.

\section{Data Collection and Analysis}

In order to obtain the data, firstly personal information form including the school, age, sex, occupational seniority and graduated university information was prepared. Afterwards, questions were prepared about the qualifications of the pre-school education program in terms of teacher and school, and pilot application was made. The obtained information was discussed with the experts who could be reached in the field and the questions were given in the final form and the application was made within the framework of permission previously received from the Directorate of National Education. The data obtained as a result of the application are tabulated taking into account the question titles and direct quotations have been made where necessary from the opinions of the teachers.

\section{Findings}

The data obtained by the data collection tool are tabulated in terms of various variables and given in this section.

Table-2. Distribution of the Participants According to Gender

\begin{tabular}{l|c|c|c}
\hline \multirow{2}{*}{ Gender } & Male & Female & Total \\
\cline { 2 - 4 } & 8 & 30 & 38 \\
\hline Percentage & 21 & 79 & 100 \\
\hline \multicolumn{4}{l}{ Source: Data have obtained from authors' field study. }
\end{tabular}

$21 \%$ of the participants were male, $79 \%$ were female. This situation is accepted as normal because it is the occupation preferred by women for preschool education.

Table-3. Distribution of the Participants According to Age

\begin{tabular}{l|c|c|c|c}
\multicolumn{5}{c}{ Table-3. Distribution of the Participants According to Age } \\
\hline Age & Male & Female & Total & Percentage \\
\hline $22-26$ & 4 & 19 & 23 & 60.5 \\
\hline $27-31$ & 2 & 8 & 10 & 26.3 \\
\hline $32-36$ & 1 & 3 & 4 & 10.5 \\
\hline $37-38$ & 1 & - & 1 & 2.7 \\
\hline Total & 8 & 30 & 38 & 100 \\
\hline
\end{tabular}

When the age of the participants is considered, it is seen to be 30 years or less with an approximate rate of $86 \%$ and it is important to get a more qualified and realistic result because of the new graduates in terms of work. The majority of participants are teachers who are new to the profession.

A total of 38 participants from 15 different universities participated in the study. When the graduated schools are considered for the 38 teaches, who are working as kindergarten teachers in Ağrı province, it is seen that 45\% of them are graduated from Ağrı İbrahim Çeçen University and Anadolu University. When the whole is taken into consideration, it can be seen that graduates from all over Turkey are found. This situation can be seen as an important result for the reliability of the research.

After revealing the general picture, 6 separate tables were created by analyzing the data in terms of the answers given by the participants and the results are presented in tabular form. 
Table-4. Distribution of the Participants According to University Graduated

\begin{tabular}{l|l|c}
\hline Item No & University Graduated & Frequency \\
\hline 1 & 19 Mayıs University & 3 \\
\hline 2 & 9 Eylül University & 2 \\
\hline 3 & A ğrı İbrahim Çeçen University & 8 \\
\hline 4 & Ahi Evran University & 1 \\
\hline 5 & Akdeniz University & 9 \\
\hline 6 & Anadolu University & 1 \\
\hline 7 & Ankara University & 4 \\
\hline 8 & Atatürk University & 1 \\
\hline 9 & Cumhuriyet University & 1 \\
\hline 10 & Çanakkale 18 Mart University & 1 \\
\hline 11 & Giresun University & 1 \\
\hline 12 & Karadeniz Teknik University & 1 \\
\hline 13 & Marmara University & 2 \\
\hline 14 & Pamukkale University & \\
\hline 15 & Selçuk University & 1 \\
\hline
\end{tabular}

Source: Data have obtained from authors' field study.

Table-5. Do you think the movement education is sufficient in pre-school education?

\begin{tabular}{l|c|c|c|c}
\hline Gender & Sufficient & Partly Sufficient & Not Sufficient & Total \\
\hline Male & 3 & 1 & 4 & 8 \\
\hline Female & 3 & 1 & 26 & 30 \\
\hline Total & 6 & 2 & 30 & 38 \\
\hline Percentage & 16 & 5 & 79 & 100 \\
\hline \multicolumn{7}{l}{ Source: Data have obtained from authors' field study. }
\end{tabular}

Considering the answers given to the question about whether the achievements in the pre-primary education program are sufficient in terms of movement education, it is revealed that $79 \%$ of the participants stated that they are not enough. This ratio indicates that the achievements in the program are insufficient to give the required movement training. As a result of the examination made, 5 out of 63 achievements belong to this area which can be accepted as proof that the results are realistic.

Table-6. Do you think you are adequate for movement education in pre-school teaching?

\begin{tabular}{l|c|c|c|c}
\hline Gender & Sufficient & Partly Sufficient & Not Sufficient & Total \\
\hline Male & 5 & 1 & 2 & $\mathbf{8}$ \\
\hline Female & 7 & 3 & 20 & $\mathbf{3 0}$ \\
\hline Total & 12 & 4 & 22 & $\mathbf{3 8}$ \\
\hline Percentage & $\mathbf{3 2}$ & $\mathbf{1 0}$ & $\mathbf{5 8}$ & $\mathbf{1 0 0}$ \\
\hline \multicolumn{2}{l}{ Source: Data have obtained from authors' field study. }
\end{tabular}

$58 \%$ of the teachers stated that they see themselves as inadequate at the point of giving motion training. As the reason of this situation, they show the inadequacy of courses for movement education during university education. $32 \%$ of those who see themselves well have shared their opinion that it would be better to have education on this area. Particularly among males, the number of those who see themselves well is $75 \%$, with some seeing partly enough. This is due to the different training they attended and the activities they participated in which was found at the end of the negotiations.

Table-7. Do you think that the schools are adequate in terms of material and facilities for the movement education in pre-school education?

\begin{tabular}{l|c|c|c|c}
\hline Gender & Adequate & Partly Adequate & Not Adequate & Total \\
\hline Male & - & 2 & 6 & 8 \\
\hline Female & 2 & - & 28 & 30 \\
\hline Total & 2 & 2 & 34 & 38 \\
\hline Percentage & 5 & 5 & 90 & 100 \\
\hline \multicolumn{2}{l}{ Source: Data have obtained from authors' field study. }
\end{tabular}

$90 \%$ of the participants gave negative answer to the question regarding the schools for the adequacy of the facilities and materials for movement training. Though male participants see themselves as sufficient at this point, it is pointed that schools seem to be inadequate in terms of facilities and materials. Some of the participants emphasize the lack of materials and facilities at the base of their inadequacy at the point of movement training.

\begin{tabular}{l|c|c|c}
\multicolumn{4}{c}{ Table-8. Have you ever get an education for movement education other than the university? } \\
\hline Gender & Yes, I got & No, I had not get & Total \\
\hline Male & 1 & 7 & 8 \\
\hline Female & 3 & 27 & 30 \\
\hline Total & 4 & 34 & 38 \\
\hline Percentage & 10 & 90 & 100 \\
\hline
\end{tabular}

Source: Data have obtained from authors' field study.

When examining the undergraduate program of pre-school education of universities, it is seen that only 3 credits, 2 hours of theoretical and 2 hours of practice named Physical Education and Play Instruction, are allocated 
to movement education. However, after 2013, this course will be combined with another lesson, Child Development Program, in the changed undergraduate program. Pre-School Games lesson was created and lessons for physical education were removed from the program. In view of the fact that $90 \%$ of the participants have not taken any courses apart from the Physical Education and Play Teaching course, the undergraduate education is inadequate in terms of full movement education.

Table-9. Are you interested in any sports?

\begin{tabular}{l|c|c|c}
\hline Gender & Yes & No & Total \\
\hline Male & 7 & 1 & 8 \\
\hline Female & 10 & 20 & 30 \\
\hline Total & 17 & 21 & 38 \\
\hline Percentage & 45 & 55 & 100 \\
\hline \multicolumn{4}{l|}{ Source: Data have obtained from authors' field study. }
\end{tabular}

Participants were asked whether they were interested in any sport and 55\% were not interested in any sport. Almost all of the men do sports in various branches, especially football, but this number is lower in the ladies. Men are interested in football, table tennis, volleyball and basketball; ladies tennis, swimming, cycling, basketball, pilates, table tennis and volleyball.

When studies on movement education are examined, it is seen that in all studies it is very closely related with other developmental areas and accepted as a prerequisite for development. In the study of Motor Developmentoriented Movement Training and Game Analysis of Motor Development in Early Childhood (2015) conducted by Sentürk et al. (2015) approximately thirty-two scientific studies were examined. In these studies, it was revealed that there is a lack of gaming studies for motor skills. The study particularly focused on the importance of development of programs for movement education in terms of psychomotor development.

In the experiment in which the effect of movement training was analyzed by Yarmkaya and Ulucan (2015) on motor development in children, 40 students participated in the study for 12 weeks with 20 children as the study group and 20 students as the control group. In the study, positive results were found for the 4-6 age group after the movement training program. In the study conducted by Sevimli-Celik et al. (2011) it has been tried to determine the perceptions of managers and parents about movement education and it has been stated that they have inadequate knowledge in this subject and it has been found out that this study in Ankara proves to be inadequate in terms of movement education in their schools. These findings coincide with the findings of our research.

\section{Conclusion and Evaluation}

According to research findings, it was observed that both schools and teachers are inadequate in terms of movement training, and teachers were asked about what needs to be done in order to correct this situation. These suggestions will be given with direct quotations so that it will be expressed more clearly.

"Firstly, good education and application facilities in the undergraduate education. Enrichment of schools with materials and classes.” E. 22.

"Children's parks can be expanded on the basis of the safety of children to do various physical activities to school gardens." E. 28.

"PE teachers may come to the kindergarten even once would be enough." E. 25.

"I think that there is a physical education teacher in the kindergarten under the branch subject. I am convinced that the consciously made activity will be more beneficial." K. 34.

"Large game rooms and interactive toys." K. 23.

"Teachers who are professional in movement education

Movement education classrooms." K. 23

"Teacher competence and sensitivity are required. The shortcomings in this area can be solved by teacher education. Institutions should support this issue at any time." K. 29.

"Sports areas should be created where children can move freely" K. 27.

"Every institution should have a sports specialist who will practice movement training. There must be open and closed areas where applications can be made. Pre-school education program should have physical education and movement education." $G$. B. Ç. 34.

"Professional teacher appointment is required for facility and material, such as physical education teacher." K. 22.

Looking at the proposal made by the teachers, it has been pointed out that at the point of movement training, especially the classes should be wide and that the sports fields should be included in more school plans. Pre-school education is regarded as an important education that requires children's education, multifaceted development and interdisciplinary cooperation.

Although the pre-school period is a basic period that should focus on movement education, it does not give importance to it and during the undergraduate education, pre-school teacher candidates have not been given as much as the lessons of motor skills. In recent years, studies have been put into practice for encouraging interdisciplinary studies. Physical education and play education courses in the curriculums of the institutions that prepare the pre-school teachers have been issued and only the play lessons in the pre-school have been given by the teachers in the pre-school teacher section. This situation is seen as a major deficiency at the point where teacher candidates are trained properly. Also, interviews with teachers seemed to admit that the teachers did not receive as much training in sports before the school. We are all aware of how the community of teachers who have inadequacies in the game will behave in communication and relationships with children.

We can all see that the inadequacy of the physical facilities in the schools together with teachers who are not interested in games and sports, and who do not have enough knowledge, creates a difficult situation. Although there were playgrounds in some schools during the trips conducted during the interviews, it was determined that there were not enough materials there. 
What should be done is aiming at applications that will contribute to the use of sports which helps to provide both physical and spiritual integration since the ancient times. The disconnection between the universities and the national education directorates is delaying the resolution of the problems in the field. Also municipalities and youth sports provincial directorates have an important share in this gap. Public institutions and organizations and private organizations need to make a very important move about sport. In particular, there is a need to educate pre-school teachers specialized in at least one branch of this field-based sport. Their training will be possible only if the preschool teachers receive post-graduate education at the academies to be established by the Ministry of Youth and Sports. This training will also be carried out in the form of graduate studies without thesis at universities, so that the aesthetic feelings that our children should possess will be trained in the best way possible to be placed by means of sports and it will be possible to look at the future more hopefully.

\section{References}

Calık, F., 2006. Child and animation. İstanbul: Morpa Culture Publications.

Celik, A. and M. Sahin, 2013. Sport and child development. International Journal of Social Science, 6(1): 467-478.

Cools, W., D.K. Martelaer, C. Samaey and C. Andries, 2009. Movementskillassessment of typicallydevelopingpreschoolchildren: A review of seven movementskillassessmenttools. Journal of Sports Science \& Medicine, 8(2): 154-168.

Gillet, B., 1975. Sports history. (Translation Mustafa Durak). İstanbul: Development.

Kerkez, F.İ., 2012. Movement and physical activity in pre-school period in children for healthy. Growth Journal of Sports Sciences, 23(1): 3442.

Ozer, D.S. and M.K. Ozer, 2004. Motor development in children. Ankara: Nobel Publication.

Ozyürek, A., İ. Ozkan, Z. Begde and N. Yavuz, 2015a. Educational program for supporting motor and social competence of preschoolers. International Journal of Science Culture and Sport, 3(Special Issue 3): 89-98. Available at: 10.14486/Ijscs261.

Ozyürek, A., İ. Ozkan, Z. Begde and N.F. Yavuz, 2015b. Sports and physical education in pre-school period. International Journal of Science Culture and Sport, 3(Special Issue 3): 479-488.

Sanders, S.W., 1992. Designing preschool movement programs. Champaign, IL: Human Kinetics Publishers.

Sentürk, U., A. Yılmaz and U. Gönener, 2015. Content analysis of game studies and movement education for motor development in preschool period. Journal of Sports Administration and Information Technologies, 10(2): 4-12.

Sevimli-Celik, S., S. Kirazci and M.L. Ince, 2011. Preschool movement education in Turkey: Perceptions of preschool administrators and parents. Early Childhood Education Journal, 39(5): 323-333. Available at: https://doi.org/10.1007/s 10643-01 1-0473-x.

Yarımkaya, E. and H. Ulucan, 2015. The effect of movement eduaction program on motor development. International Journal of New Trends in Arts, Sports \& Science Education, 4(1): 37-48.

Yıldırım, A. and H. Simşek, 2011. Qualitative research methods in social sciences. Ankara: Seçkin Yay. 